\title{
Teacher knowledge and attitudes towards inclusion: a cross-cultural study in Ghana, Germany and Spain
}

Pablo Mónico, Anthony Kofi Mensah, Matthias Grünke, Trinidad Garcia, Estrella Fernández \& Celestino Rodríguez

To cite this article: Pablo Mónico, Anthony Kofi Mensah, Matthias Grünke, Trinidad Garcia, Estrella Fernández \& Celestino Rodríguez (2018): Teacher knowledge and attitudes towards inclusion: a cross-cultural study in Ghana, Germany and Spain, International Journal of Inclusive Education

To link to this article: https://doi.org/10.1080/13603116.2018.1471526

曲 Published online: 07 May 2018.

Submit your article to this journal $₫$

Q View related articles $\sqsubset$

View Crossmark data ¿ 


\title{
Teacher knowledge and attitudes towards inclusion: a cross- cultural study in Ghana, Germany and Spain
}

\author{
Pablo Mónico ${ }^{\mathrm{a}}$, Anthony Kofi Mensah ${ }^{\mathrm{b}}$, Matthias Grünke ${ }^{c}$, Trinidad Garcia ${ }^{\mathrm{a}, \mathrm{d}}$, \\ Estrella Fernández $z^{a}$ and Celestino Rodríguez (D) $^{a}$
}

${ }^{a}$ Department of Psychology, University of Oviedo, Oviedo, Spain; ${ }^{\mathrm{b}}$ Department of Education, University of Education, Winneba, Ghana; 'Department of Special Needs Education, University of Koln, Koln, Germany;

${ }^{\mathrm{d}}$ Faculty Padre Ossó, University of Oviedo, Oviedo, Spain

\begin{abstract}
Mainstream-school teachers are the most important assets for students with special educational needs (or diverse conditions) who hope to achieve real inclusion. However, teaching experience, attitudes, and knowledge can either promote or hinder efforts towards inclusion. A cross-cultural study was conducted to examine perceptions, knowledge, and attitudes towards inclusion in teachers from Ghana, Germany, and Spain, about intervention with special-education students enrolled in their classrooms. The participants comprised 363 teachers - 156 men (43\%) and 207 women (57\%) - from three countries (Ghana, Germany, and Spain). Of the teachers, 150 (41.3\%) were from Ghana, 62 (17.1\%) were from Germany, and 151 (41.6\%) were from Spain. The results showed that there were significant differences in teachers' self-confidence and in the amount of personal and material resources they received from administrators and schools. In general, the Spanish teachers reported lower levels for these variables. All the teachers showed adequate levels of knowledge about instructional strategies and students' characteristics, although those from Ghana demonstrated significantly more knowledge than the others about students' characteristics. Finally, the teachers differed by country in terms of their attitudes towards inclusion, with the teachers from Spain and Germany demonstrating slightly better attitudes. They all agreed on the need for additional training as a key aspect in this regard.
\end{abstract}

\section{ARTICLE HISTORY}

Received 14 February 2018 Accepted 27 April 2018

\section{KEYWORDS}

Teacher; attitudes;

knowledge; inclusion; special educational needs

\section{Introduction}

There is a growing international focus on inclusion as the key to promoting the right to education, especially for children with diverse conditions (Ainscow and Sandill 2010; Hutchinson and Martin 2012). However, countries around the world face major challenges related to achieving an inclusive education system. According to the European Disability Forum (2010), integration means adapting a person to fit the environment, 
pedagogy, or organisation rather than vice versa. The opposite term, inclusion, is broader and implies a progressive change and adaptation of the educational system so that everyone's needs are met and everyone can thrive. Thus, inclusion implies two main aspects: supports and time. Real inclusion is an outcome or by-product of a process that involves integration and support over time. Along these lines, the time when a student gains a sense of belonging marks the beginning of that student's inclusion - although an exact time cannot be easily established (D'Eloia and Price 2018). Despite the varied definitions of inclusive education, Mitchell (2010) stated that students with special educational needs (SENs) must have full membership in age-appropriate classes, appropriate supplemental aids, and support services.

\section{Cross-cultural development of inclusive education}

Cross-cultural research refers to empirical studies that are carried out among members of various cultural groups who have had different experiences that have led to predictable and significant differences in behaviour. Although cross-cultural research on inclusive education is not common, some researchers have provided insight into the practice of inclusive education in various countries (e.g. Engelbrecht et al. 2017; Savolainen et al. 2012). These researchers have found differences in teachers' attitudes towards inclusive education across countries, especially because some teachers have no opportunities to train for SENs and others have better opportunities (Sharma, Forlin, and Loreman 2008).

Ghana has had a difficult history regarding legislation for disabled students. The first legislation for this population did not pass until 2006. However, in recent years, the Ministry of Education and the Ghana Education Service have made significant efforts to bring educational inclusion into regular classrooms. Since 2003, the Ghana Education Service has initiated various models to pilot inclusive education. Hayford (2013) reported that these initial projects have since expanded to over 400 schools throughout Ghana. This shows an exponential increase in the practice of inclusive education in the country. However, work remains for the broad objective of including all learners in mainstream, general-education classrooms.

In Germany, the move towards inclusive education began with pilot-school projects in the 1980s; students with diverse characteristics have since been progressively included in general education schools. Since 1990, these pilot-school projects have become the standard for German schools. There have also been many forms of collaboration between general education schools and special schools, leading to varied teaching approaches in inclusive settings. These collaborations include integrated classes, individual integration, ambulance services, and resource centres. Today, inclusion in general-education classes has extensive variety, and Germany's continuous effort reveals a systematic progression towards inclusive education.

In Spain, in the first half of the twentieth century, pupils were segregated in special-education centres. Classes were taught by specialists who had been trained to work with children who had sensory or language difficulties, intellectual impairments, or autism. In the second half of the twentieth century, experts questioned whether this system was correct. Currently, over $80 \%$ of Spanish children with SENs are integrated into ordinary schools (MECD 2018). 


\section{Teachers and inclusive education: preparedness, beliefs, and attitudes}

Heightened visibility and efforts towards an inclusive society have drastically changed the nature of special-educational provision and have had a major impact on the role of regular-classroom teachers, who must cater to the needs of an increasingly diverse group of students (Engelbrecht et al. 2015; Mitchell 2010). For researchers such as Hayford (2013), this inclusion has both social and academic dimensions. Social inclusion involves social exchanges (e.g. eating, playing, and engaging in out-of-classroom activities together) between students with diverse characteristics and conditions. Academic inclusion encompasses the ability to participate in ongoing learning activities, and it requires more training for and involvement from teachers.

Nowadays, most teachers work in contexts that include children with diverse needs. The success of inclusive education depends to a large extent on these regular-classroom teachers (Mitchell 2010), and teachers' preparedness is one of the most important factors in the successful implementation of inclusive education. However, teachers, especially those without backgrounds in diversity, may not accept responsibility for such students or may not have the skills required to assist them.

Several researchers have demonstrated the link between teachers' training in SENs, their attitudes towards inclusion, and their inclusion practices (Beacham and Rouse 2012; Florian and Black-Hawkins 2011; Sharma, Forlin, and Loreman 2008). In previous studies, scholars have revealed that many teachers are concerned about their preparedness to face diversity in the general classroom and that most teachers from regular classrooms lack the skills to implement inclusive programmes (Agbenyega 2007; Agbenyega and Deku 2011; Ocloo and Subbey 2008). This suggests that, although many teachers are willing to teach students with SENs, they often lack the necessary knowledge and teaching practices to engage in inclusive education.

In fact, in many cases, teachers believe that they are not sufficiently trained to manage diversity in their classrooms (Agbenyega and Deku 2011; Amr et al. 2016; Sharma, Forlin, and Loreman 2008). This is important because, according to Agbenyega (2007), as teachers gain the extensive professional knowledge needed to implement inclusive education, they change their attitudes. In addition, experience and contact with SEN students boosts regular teachers' confidence in working with this population, as the teachers eventually change their negative attitudes. According to Beacham and Rouse (2012), the balance among knowledge, skills, and attitudes is crucial in this case.

Teachers are more likely to maintain positive attitudes when they have the appropriate knowledge and skills to use inclusive pedagogies. The exact nature of teachers' attitudes towards inclusion is unknown, however, and the data are sometimes contradictory. Bailey, Nomanbhoy, and Tubpun (2015) observed that, although teachers had positive attitudes towards inclusion, they also had negative attitudes about the implementation of inclusive programmes in their schools. De Boer, Pijl, and Minnaert (2011) reported that several variables were related to teachers' attitudes, including training, experience with inclusive education, and the pupils' types of learning difficulties. Teachers' attitudes towards inclusion were also influenced by the amount of extra work and accommodations they had to make for these students (Agbenyega and Deku 2011).

In light of the implications for inclusive education, this study is meant to examine teachers' preparedness and attitudes concerning children with SENs and/or diverse 
conditions who are enrolled in regular classrooms; it also examines the variations between countries with different educational systems and historical backgrounds. Note that many countries' current policies advocate for the inclusion of all students in regular classrooms. Moreover, inclusive education should be developed and studied in an international perspective and using a comparative framework. This study's results should reduce tensions regarding the conceptualisation and implementation of inclusive education in generaleducation classrooms (Engelbrecht et al. 2017).

One important aspect to consider in this sense is the different proportion of students with disability or diverse educational conditions in each country. Last reports available, indicated that, from academic year 2015-2016, about 6.6\% of all students in Germany and $6.8 \%$ in Spain have an identified need for special education (Ministry of Education, Culture and Sport from Spain-MECD 2018; Sansour and Bernhard in press). In Spain, $83 \%$ of these students are integrated in mainstream schools. In the case of Germany, over $70 \%$ of learners with SEN would attend mainstream schools in early childhood education and care (ECEC); while their presence in these centres from primary and secondary education increased between 2005 and 2015, from 14\% to 38\% (European Union 2017). In the case of Ghana, however, there is not much data available, although the percentages found are significantly lower. According to the figures consulted by the authors, it is estimated that about $2 \%$ of the entire population of school going age in Ghana have some sort of disability (Ministry of Education from Ghana-MOE 2013). Concerning integration in mainstream schools, traditionally, most of the children with disabilities were enrolled in segregated boarding schools. By 2013, however, over 16.500 pupils with mild disabilities were enrolled in mainstream schools in the country, as reported by the Ghana Demographic and Health Survey 2014 (Ghana Statistical Service 2015). Nevertheless, 20\% of children age 6-14 with disability were still out of school in that year.

\section{Aims}

This study is intended to describe and compare knowledge of and attitudes towards inclusion among a wide sample of teachers from Ghana, Germany, and Spain. The main assessment instrument is an adaptation of the Attitude Towards Inclusive Education questionnaire (Przibilla \& Linderkamp, 2015), which was initially developed at Wuppertal University (Germany) and which has since been translated into several languages. This study's findings will have implications for teachers' training.

\section{Methods}

\section{Participants}

The participants comprised 363 teachers - 156 men (43\%) and 207 women (57\%) - from three countries (Ghana, Germany, and Spain). All of the participants taught at metropolitan schools. Of the teachers, 150 (41.3\%) were from 25 schools in Ghana, 62 (17.1\%) were from 12 schools in Germany, and 151 (41.6\%) were from 79 schools in Spain. The sample's mean age was 38.88 years $(S D=10.579)$. The sample characteristics are shown in Table 1 . There were statistically significant age differences among the groups, $F_{(2,360)}=92.589$, $p<.001, \eta p^{2}=.34$. The teachers from Ghana $(M=31.59, S D=6.586)$ were significantly 
Table 1. Teacher characteristics. Descriptive variables according to country.

\begin{tabular}{|c|c|c|c|}
\hline & $\begin{array}{c}\text { Ghana } \\
(n=150)\end{array}$ & $\begin{array}{c}\text { Germany } \\
(n=62)\end{array}$ & $\begin{array}{c}\text { Spain } \\
(n=151)\end{array}$ \\
\hline \multicolumn{4}{|l|}{ Gender } \\
\hline Male & $93(62 \%)$ & $14(22.6 \%)$ & $49(32.5 \%)$ \\
\hline Female & $57(38 \%)$ & $48(77.6 \%)$ & $102(67.5 \%)$ \\
\hline \multicolumn{4}{|l|}{ Age group } \\
\hline $20-30$ & $82(54.7 \%)$ & $1(1.6 \%)$ & $16(10.6 \%)$ \\
\hline $31-40$ & $51(34 \%)$ & $22(35.5 \%)$ & $38(25.2 \%)$ \\
\hline $41-50$ & $14(9.3 \%)$ & $12(19.4 \%)$ & $32(21.2 \%)$ \\
\hline $51-60$ & $1(.7 \%)$ & $23(37.1 \%)$ & $52(34.4 \%)$ \\
\hline NA & $2(1.3 \%)$ & $4(6.5 \%)$ & $13(8.6 \%)$ \\
\hline \multicolumn{4}{|l|}{ Current position } \\
\hline Regular School Teacher & $131(87.3 \%)$ & $42(67.7 \%)$ & $127(84.1 \%)$ \\
\hline Special Education Teacher & $13(8.7 \%)$ & $12(19.4 \%)$ & $24(15.9 \%)$ \\
\hline School Principal & $3(2 \%)$ & $3(4.8 \%)$ & - \\
\hline School Assistant & - & $4(6.5 \%)$ & - \\
\hline Resource Teacher & $3(2 \%)$ & $1(1.6)$ & - \\
\hline NA & - & - & - \\
\hline \multicolumn{4}{|l|}{ Grade } \\
\hline Preschool & $4(2.7 \%)$ & $3(4.8 \%)$ & - \\
\hline Lower Primary & $36(24 \%)$ & $7(11.3 \%)$ & $149(98.7 \%)$ \\
\hline Upper Primary & $63(42 \%)$ & $9(14.5 \%)$ & $2(1.3 \%)$ \\
\hline Junior High School & $44(29.3 \%)$ & $40(64.5 \%)$ & - \\
\hline NA & $3(2 \%)$ & $3(4.8 \%)$ & - \\
\hline \multicolumn{4}{|l|}{ School ownership } \\
\hline State & $132(88 \%)$ & 57 (91.9\%) & $121(80.1 \%)$ \\
\hline Non-state & $18(12 \%)$ & $5(8.1 \%)$ & $30(19.9 \%)$ \\
\hline NA & - & - & - \\
\hline \multicolumn{4}{|l|}{$\%$ students with SENs } \\
\hline $1-10 \%$ & $65(43.3 \%)$ & $30(48.4 \%)$ & $46(30.5 \%)$ \\
\hline $11-40 \%$ & $34(22.7 \%)$ & $20(32.3 \%)$ & $10(6.6 \%)$ \\
\hline $41-60 \%$ & $7(4.7 \%)$ & $2(3.2 \%)$ & - \\
\hline $61-90 \%$ & $2(1.3 \%)$ & $2(3.2 \%)$ & - \\
\hline $91-100 \%$ & $7(4.7 \%)$ & $6(9.75)$ & $3(2 \%)$ \\
\hline NA & $35(23.3 \%)$ & $2(3.2 \%)$ & $92(60.9 \%)$ \\
\hline \multicolumn{4}{|c|}{ Years of experience teaching (general) } \\
\hline $1-5$ & $71(47.3 \%)$ & $8(12.9 \%)$ & $22(14.6 \%)$ \\
\hline $6-10$ & $48(32 \%)$ & $15(24.2 \%)$ & $26(17.2 \%)$ \\
\hline $11-15$ & $14(9.3 \%)$ & $10(16.1 \%)$ & $24(15.9 \%)$ \\
\hline $16-20$ & $9(6 \%)$ & $7(11.3 \%)$ & $25(16.6 \%)$ \\
\hline $21+$ & $2(1.3 \%)$ & $21(33.9 \%)$ & $54(35.8 \%)$ \\
\hline NA & $6(4 \%)$ & $1(1.6 \%)$ & - \\
\hline \multicolumn{4}{|l|}{ Experience with SEN students } \\
\hline Yes & $65(43.3 \%)$ & $47(75.8 \%)$ & $129(85.4 \%)$ \\
\hline No & $64(42.7 \%)$ & $14(22.6 \%)$ & $9(6 \%)$ \\
\hline NA & $21(14 \%)$ & $1(1.6 \%)$ & $13(8.6 \%)$ \\
\hline \multicolumn{4}{|c|}{ Years of experience teaching SEN students } \\
\hline $1-5$ & $54(36 \%)$ & $21(33.9 \%)$ & $51(33.8 \%)$ \\
\hline $6-10$ & $10(6.7 \%)$ & $7(11.3 \%)$ & $27(17.9 \%)$ \\
\hline $11-15$ & $2(1.3 \%)$ & $3(4.8 \%)$ & $12(7.9 \%)$ \\
\hline $16-20$ & $1(.7 \%)$ & $5(8.1 \%)$ & $11(7.3 \%)$ \\
\hline $21+$ & - & $4(6.5 \%)$ & $24(15.9 \%)$ \\
\hline NA & $83(55.3 \%)$ & $62(35.5 \%)$ & $26(17.2 \%)$ \\
\hline \multicolumn{4}{|l|}{ Type of school (integration) } \\
\hline Regular School & $135(90 \%)$ & $17(27.4 \%)$ & $149(98.7 \%)$ \\
\hline Special School & $5(3.3 \%)$ & $7(11.3 \%)$ & $2(1.3 \%)$ \\
\hline Inclusive Model & $6(4 \%)$ & $17(27.4 \%)$ & - \\
\hline NA & $4(2.7 \%)$ & $21(33.8 \%)$ & - \\
\hline
\end{tabular}

Note: Sample characteristics are expressed in terms of frequency and percentage. SENs = special educational needs; NA = no answer; \% students with SENs = percentage of students with SENs whom the teacher is teaching in the current year. 
younger than those from Germany $(M=45.40, S D=9.984)$ or Spain $(M=43.44, S D=$ 9.733). Age will be used as a covariate for further statistical analyses.

Table 1 shows that, in Germany and Spain, most of the participants were women, but the opposite was the case in Ghana. The participants were mainly regular-school teachers and special-school teachers in their countries, most taught at the primary-school and highschool levels, or in state schools. The prevalence of students with SENs was between 1 and $10 \%$ in most schools. More than $75 \%$ of the teachers from Germany and Spain reported having previous experience teaching students with SENs, but in Ghana, this percentage was around $40 \%$. However, in all three countries, the teachers' experience with students with SENs ranged from 1 to 10 years. This data is consistent with the figures regarding general teaching experience. However, the percentage of teachers who reported general teaching experience of 21 or more years was higher in Germany and Spain than in Ghana. This can be explained by the composition of the sample, as the Ghanaian teachers were significantly younger than the others. Finally, most of the teachers worked at regular schools.

\section{Instruments and variables}

The Attitude Towards Inclusive Education questionnaire (Linderkamp et al. 2013) was adapted as the assessment instrument. The English, German, and Spanish versions of the instrument were used.

The questionnaire is divided into three sections made up of closed-ended and openended items. The first part is about the teachers' demographic or background information. The second part is made up of closed-ended items and uses a Likert-type scale with 4 choices (from 1, completely disagree, to 4, completely agree). Respondents reported the extent of their agreement or disagreement with each statement, thus expressing an attitude, belief, or judgment related to inclusion or about how to promote it at their schools. The last part assesses teachers' strategies, knowledge, and expectations concerning students with SENs. The reliability of the scale was high for this sample (Cronbach's $\alpha=.90)$.

For simpler data management, and based on the aims of the study, the variables were organised as follows:

- Emotional and behavioural disorders: items concerns the provision of personal, organisational and material resources for students with emotional and behavioural disorders who are enrolled in regular classrooms; the items are based on the teachers' perceptions.

- Severe intellectual disabilities: section focuses on the personal, organisational, and material resources for interventions involving students with severe intellectual impairments.

- Moderate intellectual disabilities: items relates to resources for students with moderate intellectual impairments.

- Dyslexia: this section contains items on personal, organisational, and material resources concerning interventions for students with dyslexia.

- Knowledge of teaching strategies: items relates to the teachers' perceptions of their own knowledge about instructional strategies for teaching students with diverse conditions. 
- Knowledge of students' characteristics: this section tests teachers' knowledge regarding the main characteristics of students with diverse conditions.

- Inclusion: eight items concern teachers' attitudes towards the inclusion of students with diverse conditions in the regular classroom, as well as the types of resources they should be provided with.

\section{Procedure}

Three translations of the same scale were used: in English, German, and Spanish. To ensure content and construct validity, the questionnaires were pretested. This was also done to ascertain the difficulty level of the items and the language used.

This study was conducted in accordance with the Helsinki Declaration of the World Medical Association (Williams 2008), which concerns ethical principles for research involving humans. The procedures used to select samples were non-probabilistic but were representative of the cross-cultural research population. The questionnaire was administered with the approval of educational administrations in the three countries; in Ghana, the surveys were completed with the assistance of two resource teachers, and in Spain and Germany, they were completed by post.

Considering the varied recruitment strategies used in the three countries, the participants received a common document with specific written instructions for questionnaire completion. This document also highlighted the voluntary and anonymous nature of the study.

The study's ethical considerations were based on three main aspects: informed consent, confidentiality, and the ethical use of the responses. To ensure confidentiality, the participants did not state their names on the questionnaire.

\section{Data analysis}

The data were analysed in two steps. First, the descriptive statistics for the variables were examined. The Kolmogorov-Smirnov test revealed that the data had a normal distribution, thus allowing parametric analyses to be conducted. Next, a multivariate analysis of covariance (MANCOVA) was conducted, using age as a covariable. Statistical significance was established at the level of $p<.05$. IBM SPSS Statistics V-22 was used for data processing. Specifically, magnitude of the effect by Cohen's (1988) $d$ was used, according to which the effect is small when $\eta p^{2}=.01(d=.20)$, medium when $\eta p^{2}=.059(d=.50)$, and large when $\eta p^{2}=.138(d=.80)$. Scheffé's method was used as a multiple-comparison procedure.

\section{Results}

Teachers' perceptions regarding students with emotional and behavioural disorders, severe and moderate intellectual impairments, and dyslexia

Table 2 shows the means and standard deviations for the variables related to personal, organisational, and material resources for the treatment of students with various diverse conditions. 
Table 2. Differences between groups for the intervention with students who had emotional and behavioural conditions, severe and moderate intellectual impairments, and dyslexia.

\begin{tabular}{|c|c|c|c|c|c|c|c|}
\hline & \multirow{2}{*}{$\begin{array}{c}\text { Ghana } \\
(n=150) \\
M(S D)\end{array}$} & \multirow{2}{*}{$\begin{array}{c}\text { Germany } \\
(n=62) \\
M(S D)\end{array}$} & \multirow{2}{*}{$\begin{array}{l}\text { Spain } \\
(n=151) \\
M(S D)\end{array}$} & \multicolumn{4}{|c|}{ Differences } \\
\hline & & & & $F_{5,344}$ & $p$ & $\eta p^{2}$ & Groups \\
\hline \multicolumn{8}{|l|}{ Students with emotional and behavioural conditions } \\
\hline $\begin{array}{l}\text { 1. I would be able to teach student with } \\
\text { emotional and behavioural disorders } \\
\text { (EBDs) in a general-education classroom. }\end{array}$ & $2.98(.674)$ & $2.88(.825)$ & $2.19(.736)$ & 2.953 & .050 & .017 & $1-3$ \\
\hline $\begin{array}{l}\text { 2. My school provides sufficient } \\
\text { administrative support to teach students } \\
\text { with EBDs in a general-education } \\
\text { classroom. }\end{array}$ & $2.22(.978)$ & $2.67(.787)$ & $2.40(.939)$ & 2.620 & .074 & .015 & n.s. \\
\hline $\begin{array}{l}\text { 3. My school provides sufficient time to plan } \\
\text { and prepare lessons to teach students with } \\
\text { EBDs in a general-education classroom. }\end{array}$ & $2.38(.915)$ & $2.32(.890)$ & $2.30(.885)$ & .025 & .975 & .000 & n.s. \\
\hline $\begin{array}{l}\text { 4. Students with EBDs will be academically } \\
\text { and socially successful in a general- } \\
\text { education classroom. }\end{array}$ & $2.83(.822)$ & $2.35(.668)$ & $2.68(.696)$ & 5.970 & $<.001$ & .033 & $\begin{array}{l}1-2 \\
2-3\end{array}$ \\
\hline $\begin{array}{l}\text { 5. Students with EBDs should spend most or } \\
\text { all their time in a general-education } \\
\text { classroom. }\end{array}$ & $2.61(.862)$ & $2.65(.876)$ & $2.77(.820)$ & 1.067 & .345 & .006 & n.s. \\
\hline \multicolumn{8}{|l|}{ Students with severe intellectual impairments } \\
\hline $\begin{array}{l}\text { 6. I would be able to teach student with } \\
\text { severe intellectual disabilities (SIDs) in a } \\
\text { general-education classroom. }\end{array}$ & $2.36(.918)$ & $2.40(.923)$ & $2.79(.763)$ & 10.399 & $<.001$ & .056 & $\begin{array}{l}1-2 \\
2.3\end{array}$ \\
\hline $\begin{array}{l}\text { 7. My school provides sufficient } \\
\text { administrative support to teach students } \\
\text { with SIDs in a general-education } \\
\text { classroom. }\end{array}$ & $2.04(.934)$ & $2.35(.876)$ & $2.48(.847)$ & 6.031 & .003 & .033 & $1-3$ \\
\hline $\begin{array}{l}\text { 8. My school provides sufficient time to plan } \\
\text { and prepare lessons to teach students with } \\
\text { SIDs in a general-education classroom. }\end{array}$ & $2.08(.842)$ & $2.09(.808)$ & $2.29(.780)$ & 3.155 & .044 & .018 & $1-3$ \\
\hline $\begin{array}{l}\text { 9. Students with SIDs will be academically } \\
\text { and socially successful in a general- } \\
\text { education classroom. }\end{array}$ & $2.35(.870)$ & $2.18(.869)$ & $2.58(.724)$ & 6.243 & .002 & .035 & $2-3$ \\
\hline $\begin{array}{l}\text { 10. Students with SIDs should spend most or } \\
\text { all their time in a general-education } \\
\text { classroom. }\end{array}$ & $2.21(.949)$ & $2.25(1.005)$ & $2.72(.734)$ & 17.030 & $<.001$ & .089 & $\begin{array}{l}1-3 \\
2-3\end{array}$ \\
\hline \multicolumn{8}{|l|}{ Students with moderate intellectual impairments } \\
\hline $\begin{array}{l}\text { 11. I would be able to teach student with } \\
\text { moderate intellectual disabilities (MIDs) in } \\
\text { a general-education classroom. }\end{array}$ & $2.95(.789)$ & $2.89(.851)$ & $2.97(.653)$ & .488 & .614 & .003 & n.s. \\
\hline $\begin{array}{l}\text { 12. My school provides sufficient } \\
\text { administrative support to teach students } \\
\text { with MIDs in a general-education } \\
\text { classroom. }\end{array}$ & $2.50(.918)$ & $2.60(.839)$ & $2.58(.843)$ & .104 & .901 & .001 & n.s. \\
\hline $\begin{array}{l}\text { 13. My school provides sufficient time to plan } \\
\text { and prepare lessons to teach students with } \\
\text { MIDs in a general-education classroom. }\end{array}$ & $2.45(.886)$ & $2.42(.915)$ & $2.33(.798)$ & .777 & .461 & .004 & n.s. \\
\hline $\begin{array}{l}\text { 14. Students with MIDs will be academically } \\
\text { and socially successful in a general- } \\
\text { education classroom. }\end{array}$ & $2.83(.857)$ & $2.61(1.107)$ & $2.75(.702)$ & .788 & .456 & .004 & n.s. \\
\hline $\begin{array}{l}\text { 15. Students with MIDs should spend most or } \\
\text { all their time in a general-education } \\
\text { classroom. }\end{array}$ & $2.68(.936)$ & $2.82(1.048)$ & $2.81(.728)$ & 1.448 & .236 & .008 & n.s. \\
\hline \multicolumn{8}{|l|}{ Students with dyslexia } \\
\hline $\begin{array}{l}\text { 16. I would be able to teach student with } \\
\text { dyslexia in a general-education classroom. }\end{array}$ & $2.95(.791)$ & $3.05(.858)$ & $2.82(.674)$ & 2.301 & .102 & .013 & n.s. \\
\hline $\begin{array}{l}\text { 17. My school provides sufficient } \\
\text { administrative support to teach students } \\
\text { with dyslexia in a general-education } \\
\text { classroom. }\end{array}$ & $2.43(.886)$ & $2.61(.875)$ & $2.54(.831)$ & .264 & .768 & .001 & n.s. \\
\hline
\end{tabular}


Table 2. Continued.

\begin{tabular}{ccccccccc}
\hline & $\begin{array}{c}\text { Ghana } \\
(n=150) \\
M(S D)\end{array}$ & $\begin{array}{c}\text { Germany } \\
(n=62) \\
M(S D)\end{array}$ & \begin{tabular}{c} 
Spain \\
$(n=151)$ \\
\cline { 5 - 9 }
\end{tabular} & $M(S D)$ & & \multicolumn{3}{c}{ Differences } \\
\hline $\begin{array}{c}\text { 18. My school provides sufficient time to plan } \\
\text { and prepare lessons to teach students with } \\
\text { dyslexia in a general-education classroom. }\end{array}$ & $2.53(.808)$ & $2.44(.969)$ & $2.32(.788)$ & 1.678 & .188 & .009 & n.s. \\
$\begin{array}{c}\text { 19. Students with dyslexia will be } \\
\text { academically and socially successful in a } \\
\text { general-education classroom. }\end{array}$ & $2.81(.702)$ & $2.73(1.043)$ & $2.77(.694)$ & .402 & .669 & .002 & n.s. \\
$\begin{array}{l}\text { 20. Students with dyslexia should spend } \\
\text { most or all their time in a general- } \\
\text { education classroom. }\end{array}$ & $2.73(.843)$ & $2.94(.990)$ & $2.73(.663)$ & 2.734 & .666 & .015 & n.s. \\
\hline
\end{tabular}

Note: n.s. = statistically non-significant differences.

\section{Emotional and behavioural conditions}

Some statistically significant differences existed among groups, Wilks' $\Lambda=.897 ; F_{(5,344)}=$ $3.863 ; p<.001 ; \eta p^{2}=.053$. Age was not statistically significant $(p=.431)$.

Within this component, statistically significant differences existed for two variables: Item 1 (teachers' personal resources) and Item 4 (academic and social success). Differences existed between Ghana and Spain in Item $1(p=.023)$; for Item 4 , differences existed between Germany and Ghana $(p<.001)$ and between Germany and Spain $(p=.018)$.

\section{Severe intellectual impairments}

Again, statistically significant differences existed between groups, Wilks' $\Lambda=.875$; $\left.F_{(5,344)}=4.785 ; p<.001 ; \eta p^{2}=.065\right)$. Age was not statistically significant $(p=.230)$. In this case, statistically significant differences existed in all the items, but the effect sizes were not very large.

\section{Moderate intellectual impairments}

As shown in Table 2, the teachers' scores were similar for the various items. As a result, there were no statistically significant differences between the groups in these variables, Wilks' $\Lambda=.969 ; F_{(5,344)}=1.131 ; p=.336 ; \eta p^{2}=.016$.

\section{Students with dyslexia}

Although in general terms, some statistically significant differences existed with respect to students with dyslexia, Wilks' $\Lambda=.945 ; F_{(5,344)}=2.043 ; p=.028 ; \eta p^{2}=.028$, the analysis revealed that no items reached significance when analysed individually by means of separate analyses of variance. Age was not statistically significant in any case.

\section{Teachers' knowledge of instructional strategies and students' characteristics}

Table 3 shows means and standard deviations for the items related to the teachers' perceptions of their own knowledge of instructional strategies and of the characteristics of students with diverse conditions. 
Table 3. Differences between groups in terms of teachers' knowledge of instructional strategies and students' characteristics.

\begin{tabular}{|c|c|c|c|c|c|c|c|}
\hline & \multirow{2}{*}{$\begin{array}{l}\text { Ghana } \\
(n=150) \\
M(S D)\end{array}$} & \multirow{2}{*}{$\begin{array}{l}\text { Germany } \\
(n=62) \\
M(S D)\end{array}$} & \multirow{2}{*}{$\begin{array}{l}\begin{array}{c}\text { Spain } \\
(n=151) \\
M(S D)\end{array}\end{array}$} & \multicolumn{4}{|c|}{ Differences } \\
\hline & & & & $F_{4,352}$ & $p$ & $\eta p^{2}$ & Groups \\
\hline \multicolumn{8}{|l|}{ Knowledge of strategies } \\
\hline $\begin{array}{l}\text { 1. I know and understand the instructional } \\
\text { strategies necessary to teach a student with } \\
\text { specific learning disabilities in a general- } \\
\text { education classroom. }\end{array}$ & $2.91(.746)$ & $2.88(.846)$ & $3.04(.652)$ & 1.172 & .311 & .007 & n.s. \\
\hline $\begin{array}{l}\text { 2. I know and understand the instructional } \\
\text { strategies necessary to teach a student with } \\
\text { emotional and behavioural disorders in a } \\
\text { general-education classroom. }\end{array}$ & $2.80(.805)$ & $2.78(.804)$ & $2.77(.820)$ & .796 & .452 & .004 & n.s. \\
\hline $\begin{array}{l}\text { 3. I know and understand the instructional } \\
\text { strategies necessary to teach a student with } \\
\text { severe intellectual disabilities in a general- } \\
\text { education classroom. }\end{array}$ & $2.24(.885)$ & $1.98(.983)$ & $2.24(.929)$ & 2.824 & .061 & .016 & n.s. \\
\hline $\begin{array}{l}\text { 4. I know and understand the instructional } \\
\text { strategies necessary to teach a student with } \\
\text { moderate intellectual disabilities in a general- } \\
\text { education classroom. }\end{array}$ & $2.80(.816)$ & $2.83(.867)$ & $2.68(.861)$ & 2.497 & .085 & .014 & n.s. \\
\hline \multicolumn{8}{|l|}{ Knowledge of student characteristics } \\
\hline $\begin{array}{l}\text { 5. I know and understand the characteristics } \\
\text { associated with a student with specific learning } \\
\text { disabilities in a general-education classroom. }\end{array}$ & $3.05(.747)$ & $3.05(.825)$ & $3.04(.621)$ & .103 & .902 & .001 & n.s. \\
\hline $\begin{array}{l}\text { 6. I know and understand the characteristics } \\
\text { associated with a student with emotional and } \\
\text { behavioural disorders in a general-education } \\
\text { classroom. }\end{array}$ & $3.02(.772)$ & $3.03(.730)$ & $2.80(.673)$ & 4.454 & .012 & .024 & $1-3$ \\
\hline $\begin{array}{l}\text { 7. I know and understand the characteristics } \\
\text { associated with a student with severe } \\
\text { intellectual disabilities in a general-education } \\
\text { classroom. }\end{array}$ & $2.82(.858)$ & $2.44(.958)$ & $2.45(.892)$ & 6.803 & .001 & .037 & $\begin{array}{l}1-3 \\
2-3\end{array}$ \\
\hline $\begin{array}{l}\text { 8. I know and understand the characteristics } \\
\text { associated with a student with moderate } \\
\text { intellectual disabilities in a general-education } \\
\text { classroom. }\end{array}$ & $3.05(.747)$ & $2.95(.845)$ & $2.74(.789)$ & 5.956 & .003 & .032 & $1-3$ \\
\hline
\end{tabular}

Note: 1 = Ghana; 2 = Germany; 3 = Spain; n.s. = statistically non-significant differences.

\section{Teachers' knowledge of strategies}

For this group of items, MANCOVA showed that, at a general level, there were some slight but statistically significant differences between groups, Wilks' $\Lambda=.931 ; F_{(4,352)}=3.183$; $p=.001 ; \eta p^{2}=.035$; however, age had no significant effect $(p=.283)$. The means in Table 3 show a very similar pattern of results across countries, which is supported by the lack of statistically significant effects when each item was analysed separately. Only Item 3, which is related to severe intellectual impairments, was close to reaching statistical significance $(p=.056)$. Thus, statistically non-significant differences existed between groups in these sets of items.

\section{Teachers' knowledge of student characteristics}

With respect to this second set of items, MANCOVA showed the existence of statistically significant differences among teachers across countries, Wilks' $\Lambda=.919 ; F_{(4,352)}=3.183$; $p<.001 ; \eta p^{2}=.041$. There were no differences due to age $(p=.926)$. The differences among Items 2,3 , and 4 related to emotional and behavioural disorders as well as to 
severe and moderate intellectual impairments. The most important differences existed between the teachers from Ghana and Spain. The effect sizes for these differences were small to medium.

\section{Teachers' attitudes towards inclusion}

Lastly, Table 4 shows results from the last eight items of the scale, which are related to teachers' attitudes towards inclusion. Some cross-country differences existed among the teachers. Spanish and German teachers seemed to show the best attitudes towards inclusion in this regard. This pattern of differences is supported by the MANCOVA results, Wilks' $\Lambda=.718 ; F_{(8,351)}=8.351 ; p<.001 ; \eta p^{2}=.152$. Age was statistically significant in this case, $F_{(8,351)}=2.173 ; p=.029$. The effect sizes for these differences were large. Statistically significant correlations existed between age and Items $4,5,7$, and 8 from this component, with a range of $r=.122$ to .207 . These correlations were positive in all cases, with the exception of Item 7 (Table 4), as the older teachers reported having less need for additional training and in-service development to be adequately prepared to teach students with diverse conditions.

When analysing the items separately, statistically significant differences existed for six of the eight items. Only the differences for Items 1 and 7 did not reach statistical significance (Table 4).

Table 4. Differences between groups in terms of teachers' attitudes towards the inclusion of students with diverse conditions.

\begin{tabular}{|c|c|c|c|c|c|c|c|}
\hline & \multirow{2}{*}{$\begin{array}{l}\text { Ghana } \\
(n=150) \\
M(S D)\end{array}$} & \multirow{2}{*}{$\begin{array}{l}\text { Germany } \\
(n=62) \\
M(S D)\end{array}$} & \multirow{2}{*}{$\begin{array}{l}\begin{array}{l}\text { Spain } \\
(n=151) \\
M(S D)\end{array} \\
\text { M }\end{array}$} & \multicolumn{4}{|c|}{ Differences } \\
\hline & & & & $F_{8,351}$ & $p$ & $\eta p^{2}$ & Groups \\
\hline $\begin{array}{l}\text { 1. I know how to accommodate the unique } \\
\text { needs of students with disabilities in my } \\
\text { classroom. }\end{array}$ & 3.09 (.628) & $2.97(.849)$ & $2.99(.634)$ & .635 & .531 & .004 & n.s. \\
\hline $\begin{array}{l}\text { 2. Inclusion means that students with } \\
\text { disabilities are placed into a classroom with } \\
\text { students who do not have disabilities. }\end{array}$ & $3.36(.735)$ & $2.77(.913)$ & $3.19(.727)$ & 11.208 & $<.001$ & .060 & $\begin{array}{l}2-1 \\
2-3\end{array}$ \\
\hline $\begin{array}{l}\text { 3. Inclusion means that students with } \\
\text { disabilities are supported in age-appropriate } \\
\text { general-education classes and receive } \\
\text { necessary specialised instruction within the } \\
\text { context of the core curriculum. }\end{array}$ & $3.08(.755)$ & $3.13(.614)$ & 3.39 (.643) & 6.640 & .001 & .036 & $\begin{array}{l}1-3 \\
2-3\end{array}$ \\
\hline $\begin{array}{l}\text { 4. A student with a disability who is included } \\
\text { in a general-education classroom will need a } \\
\text { special education teacher in the classroom } \\
\text { to teach him or her. }\end{array}$ & $2.93(.956)$ & $3.45(.670)$ & $2.99(.755)$ & 6.320 & .002 & .034 & $\begin{array}{l}1-2 \\
2-3\end{array}$ \\
\hline $\begin{array}{l}\text { 5. Students with disabilities should be } \\
\text { involved in all school activities with their } \\
\text { peers without disabilities. }\end{array}$ & $2.79(.877)$ & $3.42(.759)$ & $3.25(.770)$ & 11.586 & $<.001$ & .061 & $\begin{array}{l}1-2 \\
1-3\end{array}$ \\
\hline $\begin{array}{l}\text { 6. Special education teachers and general } \\
\text { education teachers need to collaborate for } \\
\text { inclusion to be successful. }\end{array}$ & $3.56(.629)$ & $3.73(.450)$ & $3.80(.401)$ & 9.113 & $<.001$ & .048 & $1-3$ \\
\hline $\begin{array}{l}\text { 7. I need additional training and in-service to } \\
\text { be adequately prepared to teach students } \\
\text { with disabilities in general-education } \\
\text { classroom. }\end{array}$ & $3.42(.582)$ & $3.44(.716)$ & $3.40(.645)$ & 1.280 & .279 & .007 & n.s. \\
\hline $\begin{array}{l}\text { 8. Students without disabilities want peers } \\
\text { with disabilities in their general-education } \\
\text { classrooms. }\end{array}$ & $2.43(.750)$ & 2.94 (.939) & $3.00(.760)$ & 12.657 & $<.001$ & .066 & $\begin{array}{l}1-2 \\
1-3\end{array}$ \\
\hline
\end{tabular}

Note: 1 = Ghana; 2 = Germany; 3 = Spain; n.s. = statistically non-significant differences. 


\section{Discussion and conclusions}

The results for the teachers' perceptions of various categories of SENs and diverse conditions showed that, in terms of emotional and behavioural conditions, the teachers from Ghana exhibited significantly higher levels of self-confidence than did their colleagues from Spain and Germany. The teachers from Ghana also had more positive expectations of these students' potential achievements in regular classrooms, even though their country's inclusion policies are not as well-established as those in the other countries. Inclusion, however, has advanced steadily. In fact, when the Ministry of Education and Ghana Education Service launched the Inclusive Education Policy in 2013, it was complemented with a comprehensive, 5-year implementation plan (2015-2019) aimed at progressively adjusting the educational system to better assist learners with SENs. This law allowed the Ghanaian Inclusive Education programme to expand from 29 districts in seven regions in 2011 to 48 districts in all 10 regions by 2013, and it provided teachers with specific training, significantly increased the percentage of children who were screened, distributed education materials and assistive devices to schools, and added a monitoring and evaluation tool as part of the policy's scale-up process (UNICEF Ghana 2016).

Generally speaking, and considering all the categories of disabilities together, in comparison to their colleagues, Spanish teachers tended to report less self-confidence and less confidence in their administrations regarding responses to students' specific needs in the regular classroom. This was particularly notable in the case of students with severe behavioural and emotional conditions. This finding could be explained through a limitation of Spanish teachers' knowledge on behavioural management strategies.

Nye et al. (2016) point out that children identified with SENs linked to behavioural difficulties may present extra challenges to educators and require additional supports, which call for specific and effective teacher training on behavioural management strategies. Other aspect to consider is the perception of the teachers on students with social, emotional and behavioural difficulties. Poulou and Norwich (2000) found that work avoidance, depressive mood, negativism, physical aggression and lack of concentration were the most problematic aspects reported by teachers regarding the intervention with this population. These characteristics of the children, together with a lack of specific management strategies may, in turn, affect teacher perception of one's competence. It would be interesting for future researchers to consider the percentage of students who are recognised as having behavioural and emotional problems in each country, to examine how they are defined, perceived and understood in each culture, and to discuss the sort of measures and specific resources that are brought into play regarding these conditions.

There is however an exception, that is the case of severe intellectual impairment. Teachers from Spain generally scored higher than those from Ghana and Germany in the variables regarding this population, highlighting Spanish administrators' and schools' higher levels of personal, organisational, and material resources for this population; while no statistically significant differences existed regarding dyslexia or moderate intellectual impairments. This could be explained by a general major concern regarding severe intellectual impairments in Spain, a population whose presence and visibility in mainstream educational scenarios has increased progressively, linked to the progressive introduction of integration policies in this country. Spain's tradition of inclusive policies is important; it 
has a long history of integration (since the 1980s) and inclusive education, and it has a relatively small number of students in segregated special-needs classes. Germany, however, has one of the highest percentages of students in special-needs schools (European Union 2017). The German educational system has been traditionally based on students' performance (Sansour and Bernhard in press); in other words., Germany has a long tradition of a three-tiered secondary educational structure, according to which students are allocated to one of three types of schools depending on their grades in primary school. This structure could be related to this finding.

Next, regarding teachers' knowledge of instructional strategies and of student characteristics, there were no statistically significant differences between countries in terms of instructional strategies. Teachers from Ghana generally reported having higher levels of knowledge about the characteristics of students with emotional and behavioural disorders and of those with severe and moderate intellectual impairments, compared to teachers from Spain and Germany. However, when looking at all three countries, the amount of knowledge that the teachers reported having about student characteristics seemed to be generally higher than their amount of knowledge about specific instructional strategies. It also worth noting that teachers from all three countries reported having greater knowledge of instructional strategies and of the characteristics of students with specific learning difficulties and emotional and behavioural conditions, when compared to their knowledge of students with moderate and severe intellectual impairments. Thus, various profiles exist for strategies versus characteristics and for various types of diversity. This means that teachers in the three countries are not receiving integrated training on SENs, which is consistent with what De Boer, Pijl, and Minnaert (2011) found: Differences in teachers' training and attitudes vary across diverse conditions.

Lastly, the teachers from the three countries exhibited positive attitudes towards inclusion in general, with those from Spain and Germany having slightly better attitudes than did those from Ghana in most cases. This could be related to the longer tradition on inclusion in Spain and Germany. Spanish and German teachers may have had more opportunities to prove inclusion's usefulness and benefits than teachers from Ghana. Nevertheless, there is also some previous research suggesting that teachers may show a negative attitude towards inclusion, as well as a negative relationship between teachers' experience and attitudes towards inclusion (Boyle, Topping, and Jindal-Snape 2013; MacFarlane and Woolfson 2013; Schmidt and Vrhovnik 2015). Schmidt and Vrhovnik found that younger teachers, and those with fewer SEN students in class (up to two students), showed a higher degree of support for inclusion than do other groups of teachers. One of the aspects that most of the research highlights, however, is the relevance of teacher pre-service and continuous training on SEN. Teachers with appropriate training would emphasise the need for change in education and encourage the development of inclusion. On the other side, factors such as oversized classes, or inappropriate knowledge and teaching aids, could hinder efforts to achieve this objective (Schmidt and Vrhovnik 2015).

Although teachers from Germany in the present study generally showed positive attitudes towards inclusion, there seems to be one exception; for the statement 'students with disabilities are placed into a classroom with students who do not have disabilities,' teachers from Germany had lower scores than did the other teachers. This could be related to the formulation of the item itself, as participants could have interpreted it as incomplete or as indicative of integration rather than inclusion (i.e. the fact of sharing a mainstream 
classroom does not necessarily mean real inclusion). As Akmese and Kayhan (2016, 2134) point out that, in order to be fully included, 'the children with SENs should receive an education in accordance with their educational needs, competence, interest and talent using the appropriate curriculum, special methods, personnel, and tools'. For this purpose, both family and teachers must be provided with specific supports. Both, family and school are two key aspects that inclusive education policies must reinforce. According to this, when a student with some sort of diversity condition is not fully included (not just integrated or mainstreamed), it does not mean that the person is not capable, but rather that the support system has failed.

Funding is a crucial issue in this sense. Sansour and Bernhard (in press) stated that funding mechanisms may have an impact on inclusive practices. For these authors, the different diagnostic procedures are linked to the possible availability of funding for inclusive education, understood in terms of investment for materials and personnel (e.g. coteaching of a special educator and a regular teacher, separated support, consultancy work, and employment of teaching assistants). In Germany and Spain, as in some other European countries, funding is commonly provided according to a child-based model, in which special services are usually obtained if a child has a diagnosis of SEN. The relationship between funding and inclusive practices can be interpreted in two different ways. On the one hand, this system seems problematic for some authors, who sustain that 'this system encourages schools to identify as many pupils with SENs as possible, since they may then generate additional economic resources for the school' (Isaksson, Lindqvist, and Bergström 2010, 134). On the other hand, previous studies show that accessibility to resources can be related to teachers' attitudes and perceptions of their own competencies in inclusive settings (Cambridge-Johnson, Hunter-Johnson, and Newton 2014). In their study, based on a sample of Bahamian teachers, $88 \%$ reported lack of resources as one of the aspects that affects their attitudes towards inclusion the most.

It is important to note in this sense that some teachers still showed a certain degree of concern regarding the ability of inclusive practices to guarantee educational quality, as has also been shown in previous studies (Bailey, Nomanbhoy, and Tubpun 2015). In addition, the teachers from the three countries agreed on the importance of teachers' involvement and collaborative work as well as on the need for additional training to boost their own skills as teachers and to promote real inclusion in the classroom, without exceptions. These teachers recognised their limitations in this area (Agbenyega and Deku 2011; Amr et al. 2016; Sharma, Forlin, and Loreman 2008) and demanded specific training. This finding is important as it suggests that teachers have a general interest in improving their understanding and skills in order to promote inclusion. However, this interest must be accompanied by economic and social policies adjusted to each country. Cultural differences, economic, political and social issues linked to each country must be considered. The inner diversity across countries that exists nowadays makes it difficult to reach an agreement on what real inclusion is, and what is appropriate for a country, culture, or population.

\section{Limitations of the study}

It is necessary to acknowledge some of this study's limitations, which may militate against the generalisation of its findings. First, there were variations in the administration of the 
questionnaire in Ghana, Germany, and Spain. Although the questionnaires were personally distributed in Ghana, they were mailed to respondents in Germany and Spain and then returned online or by post. Although specific written instructions were given to the respondents, highlighting the voluntary and anonymous nature of the study, possible biases in the participants' responses must be taken into account in future studies. Also related to the questionnaire, the statement concerning teachers' knowledge of instructional strategies may not be sufficiently descriptive of the construct that it was aimed to represent. This possible limitation in the formulation of the items should be further explored in future studies.

Second, the study only focused on students with emotional and behavioural conditions, with dyslexia, or with moderate to severe intellectual impairments. As a result, the findings cannot be generalised to other diverse conditions such as sensory impairments. Finally, it is necessary to highlight that the different sample sizes of the comparison groups may limit the scope of the findings. Research should be conducted with more balanced samples.

\section{Future research}

Regular-classroom teachers are key stakeholders in the successful implementation of inclusive education. On the whole, this study's results suggest that teachers' knowledge and attitudes towards inclusion, as well as the extent to which they feel confident in providing SEN students with appropriate educational responses, are greatly influenced by the quality of those teachers' training and by the amount of material and personal support their schools provide. These results imply that a school's organisational culture is an important aspect for future research (Mónico et al. 2017). However, it is important to note at this point that inclusive education is a process, not an event. As a result, there is a need for further research to improve evidence-based practices. Further research is also needed on teachers' efficacy and context-specific instructional practices in inclusive classrooms. It is also important to consider the new focuses that inclusive education studies should adopt in the future. If inclusion is a key question, it would be more effective to reflect on students' strengths and their ability to meet educational demands rather than on their possible disability or impairment. It is also important to examine, to a deeper extent, how the schooling environment can either favour or hinder inclusion.

\section{Acknowledgments}

This work was supported by the Region Government of Asturias under Grant [FC-15-GRUPIN14053]. We would like to thank Felicidad Valbuena and Luis Yagüez-Soberon for their collaboration and John Wyke for his language and style corrections.

\section{Disclosure statement}

No potential conflict of interest was reported by the authors.

\section{Funding}

This work was supported by the Region Government of Asturias under Grant [FC-15-GRUPIN14053]. 


\section{Notes on contributor}

Celestino Rodríguez, PhD, is an Educational Psychology Professor in Psychology Department. Vice-dean of Teacher Training and Education Faculty. Research lines focus in ADHD and learning disabilities.

\section{ORCID}

Celestino Rodríguez (D) http://orcid.org/0000-0003-4137-4503

\section{References}

Agbenyega, J. 2007. "Examining Teachers' Concerns and Attitudes to Inclusive Education in Ghana." International Journal of Whole Schooling 3 (1): 41-56.

Agbenyega, J., and P. Deku. 2011. "Building new Identities in Teacher Preparation for Inclusive Education in Ghana." Current Issues in Education 14 (1): 4-36.

Ainscow, M., and A. Sandill. 2010. "Developing Inclusive Education Systems: The Role of Organisational Cultures and Leadership.” International Journal of Inclusive Education 14 (4): 401-416. doi:10.1080/13603110802504903.

Akmese, P. P., and N. Kayhan. 2016. "Special Education Practice at Elementary Level in European Union Countries and Turkey.” Universal Journal of Educational Research 4 (9): 2134-2143. doi:10.13189/ujer.2016.040926.

Amr, M., M. Al-Natour, B. Al-Abdallat, and Hatem Alkhamra. 2016. "Primary School Teachers' Knowledge, Attitudes and Views on Barriers to Inclusion in Jordan." International Journal of Special Education 31 (1): 67-77.

Bailey, L., A. Nomanbhoy, and T. Tubpun. 2015. "Inclusive Education: Teacher Perspectives From Malaysia.” International Journal of Inclusive Education 19 (5): 547-559. doi:10.1080/13603116. 2014.957739.

Beacham, N., and M. Rouse. 2012. "Student Teachers' Attitudes and Beliefs About Inclusion and Inclusive Practice." Journal of Research in Special Educational Needs 12 (1): 3-11. doi:10.1111/ j.1471-3802.2010.01194.x.

Boyle, C., K. Topping, and D. Jindal-Snape. 2013. “Teachers' Attitudes Towards Inclusion in High Schools." Teachers and Teaching: Theory and Practice, 19 (5): 527-542.

Cambridge-Johnson, J., Y. Hunter-Johnson, and N. G. Newton. 2014. "Breaking the Silence of Mainstream Teachers' Attitude Towards Inclusive Education in the Bahamas: High School Teachers' Perceptions." The Qualitative Report 19 (42): 1-20.

Cohen, J. 1988. Statistical Power Analysis for the Behavioral Sciences. 2nd ed. Hillsdale, NJ: Erlbaum.

De Boer, A., S. J. Pijl, and A. Minnaert. 2011. "Regular Primary Schoolteachers' Attitudes Towards Inclusive Education: A Review of the Literature." International Journal of Inclusive Education 15 (3): 331-353. doi:10.1080/13603110903030089.

D'Eloia, M. H., and P. Price. 2018. “Sense of Belonging: Is Inclusion the Answer?” Sport in Society 21 (1): 91-105. doi:10.1080/17430437.2016.1225819.

Engelbrecht, P., M. Nel, N. Nel, and D. Tlale. 2015. "Enacting Understanding of Inclusion in Complex Contexts: Classroom Practices of South African Teachers." South African Journal of Education 35 (3): 1-10. doi:10.15700/saje.v35n3a1074.

Engelbrecht, P., H. Savolainen, M. Nel, T. Koskela, and M. A. Okkolin. 2017. "Making Meaning of Inclusive Education: Classroom Practices in Finnish and South African Classrooms." Compare: A Journal of Comparative and International Education 47 (5): 684-702. doi:10.1080/03057925. 2016.1266927.

European Union. 2017. Education and Training Monitor 2017. Country Analysis. Luxembourg: Publications Office of the European Union. https:/ec.europa.eu/education/sites/education/ files/monitor2017-country-reports_en.pdf. 
Florian, L., and K. Black-Hawkins. 2011. "Exploring Inclusive Pedagogy.” British Educational Research Journal 37 (5): 813-828. doi:10.1080/01411926.2010.501096.

Ghana Statistical Service (GSS), Ghana Health Service (GHS), and ICF International. 2015. Ghana Demographic and Health Survey 2014. Rockville, MD: GSS, GHS, and ICF International. https:// dhsprogram.com/pubs/pdf/fr307/fr307.pdf.

Hayford, S. K. 2013. Special Educational Needs and Quality Education for all. Winneba: Special Education Books.

Hutchinson, N. L., and A. K. Martin. 2012. Inclusive Classrooms in Ontario Schools. Toronto: Pearson. Isaksson, J., R. Lindqvist, and E. Bergström. 2010. "Pupils with Special Educational Needs: A Study of Assessments and Categorizing Processes Regarding Pupils' School Difficulties in Sweden.” International Journal of Inclusive Education 14 (2): 133-151.

MacFarlane, K., and L. Woolfson. 2013. "Teacher Attitudes and Behavior Toward the Inclusion of Children with Social, Emotional and Behavioral Difficulties in Mainstream Schools: An Application of the Theory of Planned Behavior." Teaching and Teacher Education 29: 46-52. doi:10.1016/j.tate.2012.08.00.

MECD (Ministry of Education, Culture and Sports from Spain). 2018. Data and Figures in Spain. Course 2017/2018. Education.2017 Edition. Madrid, SP: Secretaría General Técnica.

Mitchell, D. 2010. Education that Fits: Review of International Trends in the Education of Students with Special Educational Needs. Final report of special education review. Canterbury: University of Canterbury.

MOE (Ministry of Education from Ghana). 2013. Inclusive Education Policy. Draft. http://www. voiceghana.org/downloads/MoE_IE_Policy_Final_Draft1.pdf.

Mónico, P., S. Pérez-Sotomayor, D. Areces, C. Rodríguez, and T. García. 2017. “Coping Strategies in Specific Educational Support Needs and Teacher Burnout.” Revista de Psicología y Educación 12 (1): $35-54$.

Nye, E., F. Gardner, L. Hansford, V. Edwards, R. Hayes, and T. Ford. 2016. “Classroom Behaviour Management Strategies in Response to Problematic Behaviours of Primary School Children with Special Educational Needs: Views of Special Educational Needs Coordinators." Emotional and Behavioural Difficulties 21 (1): 43-60. doi:10.1080/13632752.2015.1120048.

Ocloo, M. A., and M. Subbey. 2008. "Perception of Basic Education School Teachers Towards Inclusive Education in the Hohoe District of Ghana." International Journal of Inclusive Education 12 (5-6): 639-650. doi:10.1080/13603110802377680.

Poulou, M., and B. Norwich. 2000. "Teachers' Perceptions of Students with Emotional and Behavioural Difficulties: Severity and Prevalence." European Journal of Special Needs Education 15 (2): 171-187. doi:10.1080/088562500361600.

Przibilla, B., and F. Linderkamp. 2015. "Development and Validation of an Online-Survey to Measure Inclusive Competence and Attitudes of Teachers." World congress on learning disabilities "research to practice: academic and social-emotional learning" der learning disabilities worldwide (LDW), Venice, Italy,September.

Sansour, T., and D. Bernhard. in press. "Special Needs Education and Inclusion in Germany and Sweden." ALTER, European Journal of Disability Research, doi:10.1016/j.alter.2017.12.002.

Savolainen, H., P. Engelbrecht, M. Nel, and O. P. Malinen. 2012. "Understanding Teachers' Attitudes and Self-Efficacy in Inclusive Education: Implications for Preservice and in-Service Teacher Education." European Journal of Special Needs Education 27 (1): 51-68. doi:10.1080/08856257.2011.613603.

Schmidt, M., and K. Vrhovnik. 2015. "Attitudes of Teachers Towards the Inclusion of Children with Special Needs in Primary and Secondary Schools.” Hrvatska revija za rehabilitacijska istraživanja 51 (2): 16-30.

Sharma, U., C. Forlin, and T. Loreman. 2008. “Impact of Training on Pre-Service Teachers' Attitudes and Concerns About Inclusive Education and Sentiments About Persons with Disabilities.” Disability \& Society 23 (7): 773-785. doi:10.1080/09687590802469271.

UNICEF Ghana. 2016. Accessed March 2018. https://20cxh614hon119kmcx49v25h-wpengine.netdnassl.com/wp-content/uploads/2016/02/257_Ghana_Inclusive-Education-rolled-out-throughoutGhana.pdf.

Williams, J. R. 2008. “Revising the Declaration of Helsinki.” World Medical Journal 54: 120-125. 